\title{
TECHNOLOGY SELLING SEX VERSUS SEX SELLING TECHNOLOGY
}

Konstantinos Michos

Aristotle University of Thessaloniki, Greece konmichos@gmail.com

\begin{abstract}
The object of this study is to conduct a semiotic analysis of two different websites' advertising techniques: one that promotes sex toys by emphasising their technological superiority, and another promoting technology products by employing content of a sexual nature to increase their appeal. By studying and comparing these approaches, useful conclusions can be drawn about the way digital tools utilize the concepts of sex and technology. Digital communication makes use of many different modes, and it is interesting to see both how these are employed to represent sex and technology in digital media. Results show that interactivity plays an important role in the experience and messages delivered by the websites, while sex and technology are presented as opposites and used in balance.
\end{abstract}

Keywords: digital marketing, sex/technology products, webpages, multimodality 


\section{Introduction}

The use of material objects in order to enhance romantic or sexual life is not new, dating back to the $\mathrm{BC}$ era. Every time technology leapt forward, newfound discoveries would find a way into commercial markets, including sex-related products. Marketing would then further develop the products, adding value, status and recognition. This process is even more evident in the present era of the Internet of Things: digital ads have more ways of reaching us and many of them feature products that promise to enhance our romantic and sexual relationships.

On the other hand, the idea that "sex sells" has been identified as a common marketing strategy, despite its controversial effectiveness (Treise, Weigold, Conna \& Garrison 1994: 65) and lack of relation to the nature of the product. Sexually charged content has been used to promote anything from clothing and cosmetics to drinks and food. Lately, as technological products and smart devices are becoming mainstream, this kind of advertising strategy is being employed to a greater extent.

This article studies the marketing techniques employed in digital texts that promote products related to sex and technology. Our purpose is to reveal how the new semiotic modes afforded by digital media function in contrast to traditional ones. Interestingly, sex and technology can act both as products and as marketing points. This observation leads to the following research questions: How are the modes offered by digital media being used in order to represent sex and technology? Does their function as products or as selling points affect the observed outcome? Are there any differences compared to traditional media? In order to answer these questions, structural elements present in the websites will be studied, particularly their denotative and connotative functions. Possible intertextual references in the sample will be also discussed, followed by conclusions concerning the multimodal character of the websites under scrutiny.

\section{The study of advertisements}

Semiotic analysis of advertisements initially focused on printed ads (Barthes 1964) but has evolved greatly over time. Researchers expanded their study in order to include advertising in other forms of media. Examples include Crisell (1994) on radio communication and advertising, as well as Budd, Craig \& Steinman (1999) and Thibault (2000) on television commercials. Lately, the increased popularity of the internet has spurred great interest in digital marketing and other forms of digital media (Robinson, Wysocka \& Hand 2007; Roehm \& Haugtvedt 1991; Stewart \& Pavlou 2002). This is justified by the fact that digital media can employ many new and different modes of communication and combine them, with varying levels of interaction, in order to present information and create meaning in ways not feasible before. 
As content of a sexual nature has been extensively used in all forms of advertising, there has also been a lot of research on its role and effectiveness in marketing. From a semiotic point of view, sexual content can be identified and described by the following typology: nudity, sexual behaviour, physical attractiveness, sexual referents and sexual embeds (Nedeljković, Puškarević, Novaković \& Pinćjer 2013).

Nudity refers to the quantity and quality of clothes and accessories worn by models in advertisements. Nude or semi-nude imagery does not always allude to sex appeal but is closely related to it. Sexual behaviour includes the actions of actors in the advertisement, whether these actions are targeted to themselves, to other actors in the scene, or to the viewer. Physical attractiveness describes all the elements used in order to present beauty. Models chosen for their impeccable physical appearance, makeup, lighting and photographic equipment as well as digital manipulation are used to increase levels of physical attractiveness. Sexual referents are the elements that are not themselves of a sexual nature but can be perceived as such in context. Innuendos or the use of specific stylistic approaches to the scene and music fall into this category. Finally, sexual embeds-better known as subliminal advertising-refer to content perceived subconsciously by viewers, like explicit images hidden within a larger frame.

\section{Methodology}

The study will be based on semiotic notions largely used in advertising such as connotation, intertextuality and, mainly, multimodality. The study of connotations is especially important in advertising, as connotations are cultural signs. According to Barthes' (1964: 49) analysis, connotations are second order semiotic systems or simply ideologies. Barthes (2002 [1973]: 9) mentions that, semiologically, each connotation is the starting point of a code, the articulation of a voice which is woven into the text. It is only natural to expect connotations to be used in "texts" where denotations not only downgrade them, but in all probability also prevent them from successfully communicating the intended meaning. This is even more true if the visual elements used are indexes ${ }^{2}$, which in my opinion is a more bold choice because it leaves the imagination raging. As Sebeok (1987: 24) claims, "[i]n the marketing of goods, services and ideas auxiliary

\footnotetext{
${ }^{1}$ As the Tartu-Moscow School of Semiotics claims, "the concept of 'text' is used in a specifically semiotic sense and, on the other hand, is applied not only to messages in a natural language but also to any carrier of integral ('textual') meaning - to a ceremony, a work of the fine arts, or a piece of music' (Uspenskij et al. 2003 [1973]: 297).

${ }^{2}$ According to Peirce (2.247-2.249, c. 1903), "a sign can refer to an Object by virtue of an inherent similarity ('likeness') between them (icon), by virtue of an existential contextual connection or spatiotemporal (physical) contiguity between sign and object (index), or by virtue of a general law or cultural convention that permits sign and object to be interpreted as connected (symbol)".
} 
verbal and nonverbal messages are normally implied - in marketing, semiotics plays necessarily a relevant, if only auxiliary role [...]".

The appearance of new forms of interaction and communication because of new technological advancements is closely related to multimodality. Simply put, multimodality is the combination of different types of modes of communication in a single text. Kress (2001: 1) mentions that popular and high-culture arts "[...] have begun to use an increasing variety of materials and to cross the boundaries between the various art, design and performance disciplines, towards multimodal Gesamtkunstwerke, multimedia events, and so on." Indeed, digital media make use of all channels of communicationtext, image, sound, haptics etc.-and are therefore multimodal in nature. O'Halloran (2011: 1) says that " $[\mathrm{m}]$ ultimodal discourse analysis [...] extends the study of language per se to the study of language in combination with other resources, such as images, scientific symbolism, gesture, action, music and sound". It is exactly the novelty of the multimodal interactions offered by digital media that presents great semiotic interest.

In fact, the possibilities presented by the multimodality of digital media are so many and diverse that even years after computers entered our daily lives, we are still amazed by the creativity following any introduction of new hardware and software. It is the "moment of explosion", the "unpredictable" mentioned by Lotman (2009: 7): "[f] orward movement arises in two ways. Our sense organs react to minor stimuli, which, at the conscious level, are perceived as continuous movement. In this sense, continuity represents a perceived predictability, the antithesis of which is unpredictability, a change occurring in the form of explosion".

The combination of different modes of communication in digital media also allows for greater degrees of intertextuality: any text is influenced by other texts, and it is only expected that a multimodal text would have multiple influences. The term was coined by Kristeva, who mentions that "[a]ny text is constructed as a mosaic of quotations; any text is the absorption and transformation of another" (Kristeva 1986: 37). There are many different ways intertextuality can manifest in a text, with anagram, allusion, adaptation, translation, parody, pastiche and imitation being some of the most referenced (Baldick 2001: 128). The use of intertextuality in advertisements makes them more memorable, although this is not the only reason it is employed. Discussing commercials within the flow of television programs, Stam (1992: 203) discusses that "self-referential humour signals to the spectator that the commercial is not to be taken seriously, and this relaxed state of expectation renders the viewer more permeable to the commercial message".

Even when many modes are combined together, verbal texts still retain a significant role within websites. It is therefore important to include in the study the typography employed in the websites. With all the digital assets available today to creators, the choices made in typography are all but 
random. They, too, act as meaning carriers. Van Leeuven (2006: 148-152) suggests approaching the semiotics of typography by observing the following characteristics: weight (bold or regular characters); expansion (relative to the horizontal space occupied); slope (leaning of letters); curvature (the use of curves in the letters or absence thereof); connectivity (whether characters appear formed by a single line); orientation (change in horizontal and vertical dimensions ratio); regularity (whether all characters adhere to the same stylistic rules or not); and finally non-distinctive features (decorative elements like serifs). He clearly states though that the meaning of a particular font's characteristics greatly depends on its context.

\section{Sample}

The sample includes two websites whose aim is primarily to promote specific products, rendering them digital advertisements. The first one $e^{3}$ is the website of a sex-toy company, Lovense. The specific site studied showcases one of their products and is designed to achieve multiple goals: to present information about the product and the company (technical specifications, communication data), to promote sales, and also to offer the possibility of placing orders, acting as an online store. The specific product was chosen because its main selling point is the use of modern technology (Bluetooth connectivity, dedicated smartphone application, advanced mechanical motors) in order to provide enhanced sexual pleasure. In other words, the product is sex-related but the marketing used is technology related.

The second website ${ }^{4}$ was created for marketing purposes only. It was developed in March 2006 by FCB Vienna advertising company for Cosmos, an Austrian company selling consumer electronics and household appliances. It was created as an online calendar with pictures of young people engaging in fetish erotic practices using products from the advertised company. The purpose of the campaign was to appeal to a younger audience and this is the reason explicit sexual content was used. The website was a mini-site; mini-sites are a marketing tool employed for internet promotion and focus on the creation of material that can become viral. They often rely on the element of surprise: viewers do not know initially if the website they are browsing is related to the advertised brand. Indeed, the address of the original site was www.hitech-fetish.com and had no logos or other information that related to Cosmos on the frontpage. The advertising message was revealed only if the viewer followed specific clues that were provided. Since the hosting of sites include costs, mini-sites are only available for the duration of the promotional event and so in this case, related material was

\footnotetext{
${ }^{3}$ See https://www.lovense.com/bluetooth-remote-control-vibrator (last accessed on 14/10/2018).

${ }^{4}$ See https://www.bitbite.at/hitechfetish/index.html (last accessed on 14/10/2018).
} 
retrieved from backup websites. The site was successful in creating a viral response in Austria. In fact, the success prompted the product company to make five hundred printed versions of the calendar that were subsequently sold online in two weeks 5 .

\section{Results}

\subsection{Technology selling sex}

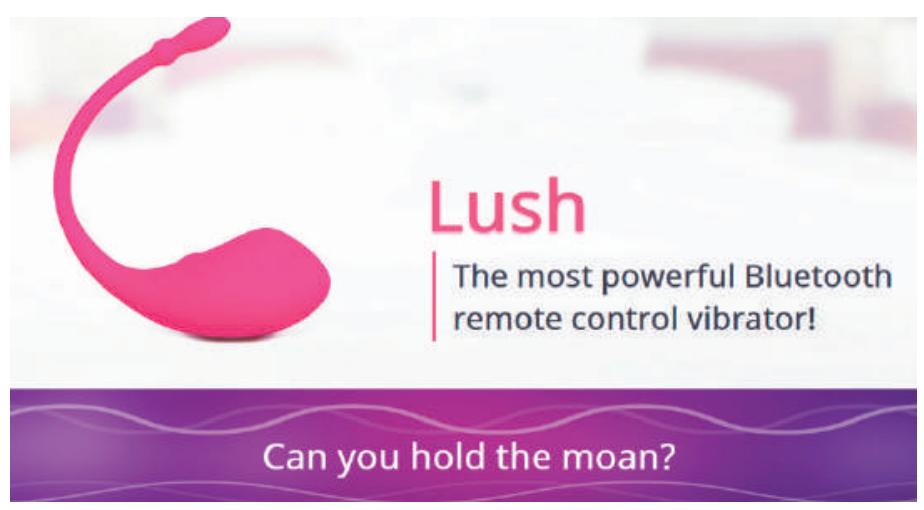

Fig. 1: Frontpage of the first website of the sample

A first glance at the website of the sex-toy shows the product next to its commercial name, Lush. There is a strong use of colour, mostly pink and white. Pictures include photographs of the actual product but no photographs of people are shown, only simplistic outline sketches of people using the product. Verbal elements are present throughout the webpage but the majority of them are technical in nature, advertising the superiority of the specific model. Marketing catchphrases are inserted infrequently (e.g. "Can you hold the moan?" at the top of the webpage) but any actual benefits of the use of the product (like increased pleasure) are mostly implied with no details about them offered directly.

What is the justification for these choices? Pink connotes femininity and matches the fact that the product is designed to be used by women. White is linked to innocence and transparency (see Van Leeuwen 2011: 3). Indulgence in sexual pleasure is often combined with feelings of guilt so this choice of colour aims to defend the intentions of the site: ${ }^{6}$ it is not a porn site. Similarly, more detailed images are avoided to reduce the risk of creating feelings of shame or other moral conflicts to viewers. In other words,

\footnotetext{
${ }^{5}$ See https://www.adforum.com/creative-work/ad/player/6696991/hitech-fetish/cosmos (last accessed on 14/10/2018).

${ }^{6}$ As van Leeuwen (2011: 11) argues " [...] colour can be used 'textually', to create coherence between the different elements of a larger whole [...]".
} 
the actual use of the product is implied through indexes and not shown directly through icons. As for the name of the product, it is a pun, a combination of the words "lust" and "hush". The name betrays the basic qualities of the product: it is a silent vibrator.

However, these verbal and non-verbal elements could also be available for decoding in a theoretical, printed version of the site. What is more interesting to study is the presence of elements that can only be experienced when viewing the website on a computer screen. In this regard, this multimodal text uses three digital assets.

Firstly, a section featuring images of a smartphone screen shows the application accompanying the product running. Interactive buttons next to it (left arrow and right arrow) offer the ability to change the image, thus creating a virtual tour of the application. Other buttons allow the direct installation of the application for further testing on the viewer's smartphone. This section has obvious practical benefits, as potential customers can directly interact with the software of the product. This way they can better decide whether to buy it or not. More importantly, by making available a virtual experience of the software, the company advertises two important characteristics: ease of use and trust. The fact that the application has easy to navigate menus is only punctuated by the fact that the website - which the viewer has already been browsing for some time now - is also easy to navigate and offers all necessary information to customers. Also, the fact that there is a "Download" button builds a feeling of trust as it showcases the legitimacy of the company and distances it from scam territory. Anyone can verify that the software is actually real by downloading it.

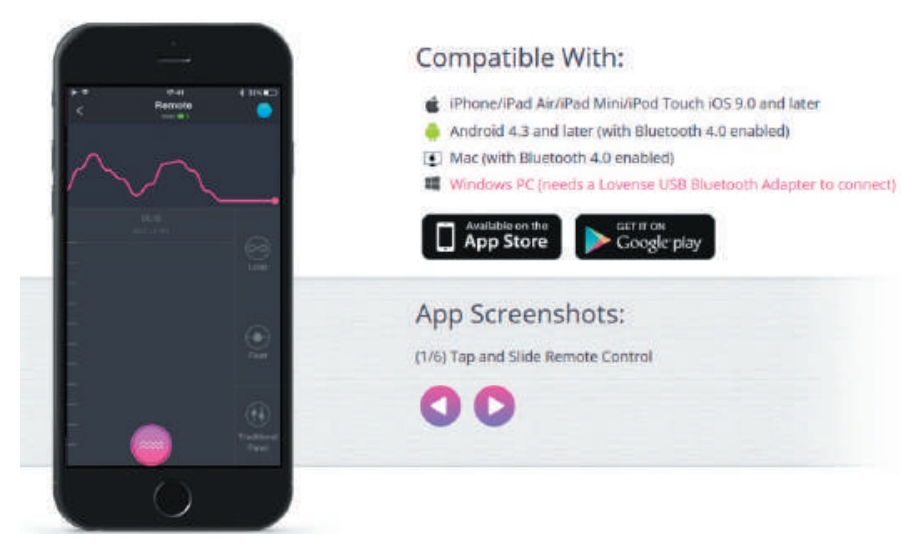

Fig. 2: Smartphone interactivity 
Secondly, a short video clip shows the product functioning next to a competing product in order to demonstrate the acoustics, which is a major selling point. This also conveys trustworthiness: the product functions exactly as promised but also proves that the company is aware of the fears and anxieties of customers and strives to mollify them.

\section{More discreet than vibrating panties or other wearable vibrators!}
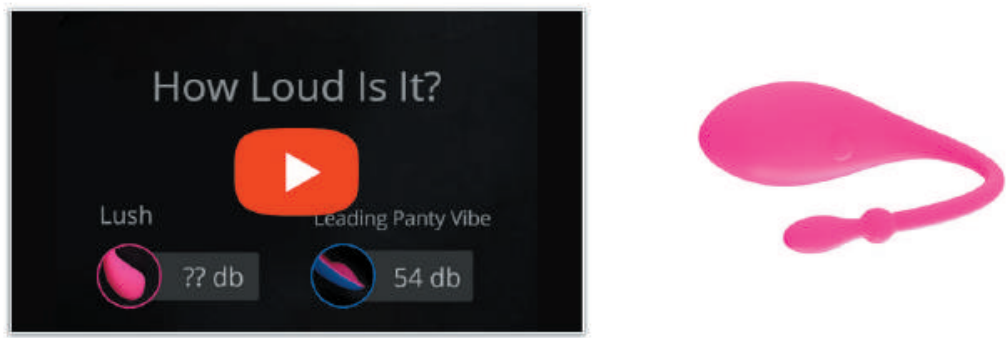

Fig. 3: Incorporation of video

Finally, in another section, an image of the product is shown next to images of competing products. By hovering the mouse cursor over the images, they become slightly magnified. The zoom-in is subtle, which means its goal is not to provide added visual information, an otherwise common feature in online shops. The fact that the same animation is not used on the company's product but only for competing ones further solidifies that. The magnified image is surrounded by a ring and the whole animation resembles the actual activity of using a magnifying glass. The way competing products are presented (under a virtual magnifying glass) is an attempt to present them as having something to hide. This kind of animation could be an intertextual reference to another kind of advertisement, those promoting detergents and soaps, where a similar zooming animation reveals the presence of microbes. This certainly creates a humorous and relaxing moment for the user browsing the site, whose inhibitions present a threat to the anticipated sale, while at the same time presenting competing products as suspicious.

The typographical elements used are in accordance with the ideas presented. The weight remains low in order to show calmness and discretion; there is little curvature in order to distance the reader from indecisiveness and secure trust in the product. The rounded corners of the letters point to femininity but also the roundness of the product which renders it soft and therefore safe. The lack of connectivity and serifs mainly increases the legibility of texts, which is expected in an advertisement. But at the same time it maintains the trustworthiness and professionalism that is gradually being built throughout the site. In a couple of occasions italics are used ("Nearly 
Silent When Inserted, Use without worrying about roommates, family, or strangers in public hearing it!") and they correspond to an act of whispering. Sounds must be kept low, similarly to the toy, and an increased level of intimacy is created. One exception is the name of the product right in the beginning, which has some light shadowing effect to increase its volume.
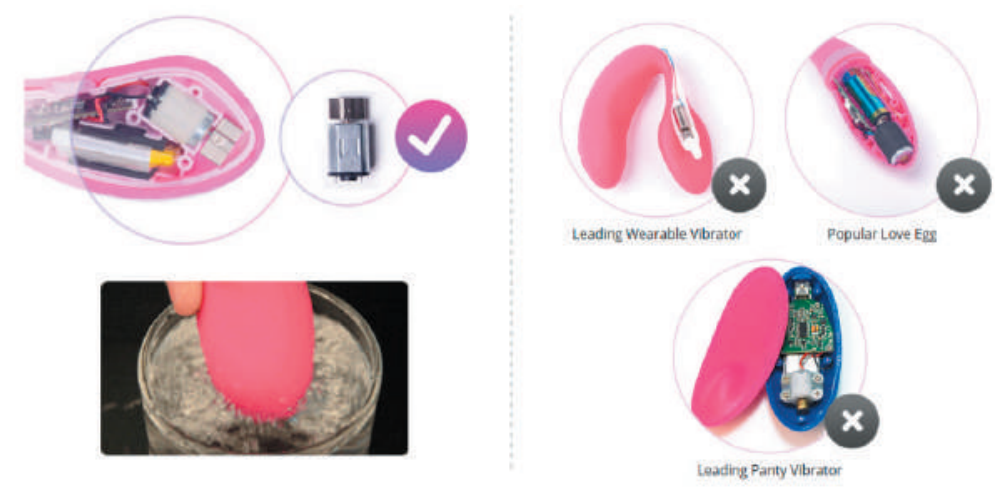

Fig. 4: Animated comparison to other products

The only type of sexual content found on the website are sexual referents. There is a distinctive lack of actual people being depicted. The most explicit images are some graphical outlines showing parts of a female body and a short animation of the vibrator in a glass of water. The purpose is to demonstrate its vibrating power by showing the small droplets of water hopping out of the glass. A different image to achieve the same goal would be letting the vibrator on a table with sand while in operation, droplets being substituted by the grains of sand: but that would completely distort the message, whose function is to connote the female genitalia.

The persistent effort to avoid triggering guilt is an unpredictable finding: considering that household products have been advertised in ways often reaching obscenity, it is rather interesting to observe a sex-toy advertisement whose purpose is to offer pleasure so focused on subtlety.

\subsection{Sex selling technology}

The introductory webpage of the campaign asks for age verification in order to allow entrance to the main site. The text is in German and so are the rest of the verbal elements, matching the language of the target audience. From the beginning it is evident that the content is going to be much more explicit than that of the previous site. While it is logical that such a measure is obligatory in order to remain within legal limits, it also acts as a first hint of the content of the site: this kind of age verification is usually 
asked in porn sites. The prevalent colour is black and its purpose is exactly the opposite compared to the previous website. Dark tones are used to signify deviant sexual desire and a lack of innocence.

As soon as age confirmation is given, a short video clip starts playing, showing scenes from the photo shooting of the event. An interactive button allows to skip the video. To this point, no explicit images are yet shown in the video. The "Skip" button acts as a secondary consent mechanism. This time, however, a small sample of the content is given to the viewer (the video clip). Even if someone accidentally reached the original frontpage and did not know what kind of website they were visiting, there is no excuse now. Proceeding any further turns the viewer into a kind of accomplice, a feeling of guilt is gradually cultivated. This synergizes with the use of sound elements. For the duration of the clip, a piece of electronic music is played, suitable to the "porn" atmosphere created. If the viewer does not skip the video until it ends, another interactive button appears that was not present earlier, which allows re-watching the video. This further builds guilt: the video is something that the viewer might have enjoyed, and this is why an opportunity is given to watch it again.

After the short video, the viewer is taken to the main and final part of the webpage. A similar kind of music is playing and twelve images are rotating on the screen, one for every month of the calendar. However, the images have no indication of month/day names, dates, or other calendar information. This makes it clear that the purpose of the calendar is not to be informational but rather aesthetically pleasing. The only thing offered is the aesthetics of a pin-up calendar.

This webpage offers additional interactive features. First, it allows the viewer to change the music and choose between three distinct pieces (of the same genre), or totally disable it. The user can control rotation of the images through movements of the mouse. The setting creates a scene of voyeurism: the sexually explicit photos rotate in front of the viewer, who is in total control of the music, the motion, everything. Second, there is interaction with the photos themselves. By clicking on them, a zoomed-in version appears and is accompanied with options to download the picture in various resolutions to use as a background image. Photos show the models taking part in fetish sexual practices, usually nude. In each photo, a household device is part of the narrative, like cables of electronic devices being used for bondage etc. The message is that these devices can be sources of pleasure and the images are worth saving for viewing again later.

In certain instances, the devices in the pictures will flash yellow, a hint that further interaction can take place by clicking on it. Such a signification is often used in video games. Considering the audience is using a computer for accessing the website, it is probably assumed that viewers can decode the sign and proceed by clicking the items. In doing so, they are introduced 
to a pop-up text that constitutes the actual advertisement: a short text describing the device, its technical specifications and current, reduced price at the shop. No option for online sale is offered; the site has purely promotional purposes. The pop-up test acts as comic relief for the sexual tension built up throughout the experience. No further hints are offered from this point on, but it is logical to assume that viewers will try to interact with all twelve images, curious to see the advertisement text in all of them.

A final level of interactivity is implied, also borrowed from video game culture. In certain kinds of video games, clicking on the screen with the mouse cursor is encouraged in order to explore items and reveal more interactive elements. Sometimes these elements are hidden in the sense that no visual clues are given to the player. If the secret is found, the player is rewarded in some way for their patience and insight. If website viewers are accustomed to playing video games, it is expected that they might assume more interactive elements are hidden in the images, keeping themselves motivated to continue clicking on the pictures on other areas of the photos that do not flash yellow. In this way, a kind of sexual interaction may start: viewers can click on the naked bodies of the photographed models hoping and expecting a response. This way, the digital interactive elements of the website are used to simulate an activity that would otherwise be impossible by means of traditional communication channels.

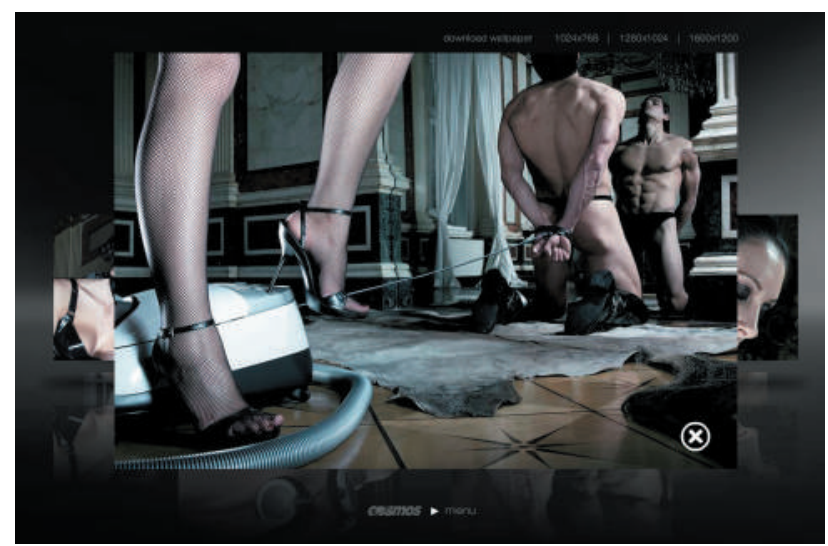

Fig. 5: Typical view of the advertising campaign site

There are many minor intertextual references to pornographic material in this website: music, the age verification, the pin-up style of the photographs. Perhaps the strongest intertextual reference lies in the content of the images themselves. The models-carefully chosen for their physique-are shown in large, luxurious rooms that resemble a mansion, their clothing and make-up is exquisite, while the production value of the photo shoot is obviously high. The whole setting is similar to orgy scenes in movies, like Stanley Kubrick's 
"Eyes wide shut". The message of extravagance and sexual indulgence is very clearly defined as a polysemiotic text, along with interactive operations that compose a multimodal canvas for the advertised product.

Typographical information in the advertisement is limited because its verbal messages are limited. The pop-up message promoting the products and their price has all the characteristics required to identify it as a part of a technology store's product catalogue. Other than that, similar findings as in the first webpage are also valid here: the letters used remain as simple as possible to facilitate reading. But this lack of verbal text also signifies something else: this is not a place for words but for action. Lack of verbal text along with the absence of capital letters in the beginning of words also connotes a low profile and maintaining discretion.

Visual elements used are icons and leave nothing to the imagination. Every type of sexual content is used (nudity, sexual behaviour, physical attractiveness and sexual referents), except for embeds. The frequent use of sexual imagery has a desensitizing effect and this kind of campaign would probably not be considered unique today. But the element of surprise lies in the kind of the products promoted. The overall style evokes images of lifestyle products such as perfumes or alcohol drinks. In comparison with the sex-toy website which dealt with the sexual act itself but remained discreet, the surprise in this advertisement is even greater.

\section{Discussion}

One unanticipated and interesting finding of this study was related to the portrayal of sex and technology concepts in digital media. Both sample websites had either denotations or connotations of these concepts but used them in a balanced manner. The first product is linked to sexual pleasure itself, but its promotion is based on its technological superiority. In the second example, products are everyday technological devices which are given sexual appeal to make them appear more desirable. In both cases, sex and technology seem to take up opposing places on an axis (see Fig. 6). On the one hand, technology is linked with concepts like "performance", "reliability", "safety" and "political correctness". On the other end of the spectrum, sex is linked with concepts like "pleasure", "indulgence", "appeal" and "taboo".

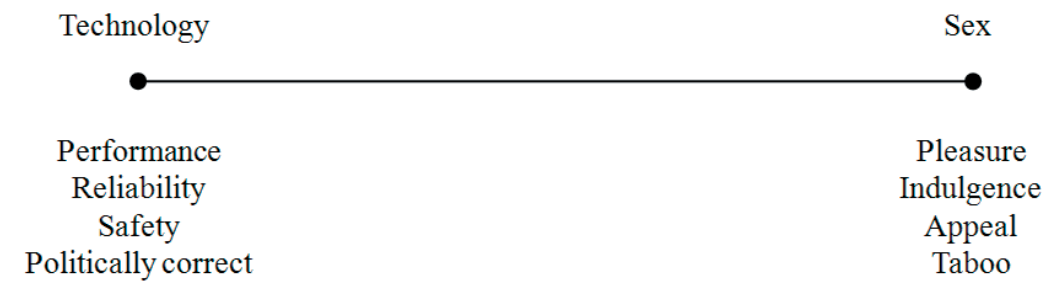

Fig. 6. The opposing concepts linked with sex and technology in digital media 
Sex and technology are by no means concepts opposite to each other, but the fact that two completely different advertisements treated them as such is worth pointing out.

\section{Conclusions}

Two websites promoting products related to sex and technology were analyzed in order to study the use of digital modes in advertising. It was revealed that an abundance of information was codified in the websites, employing different modes: text, image, sound, animation, typography, interaction. In order to maximise the impact of multimodal texts, more resources are clearly required when compared to traditional texts. But the multimodal approach used in the sample websites was effective in communicating the intended message, considering the viral success reported. The most important mode identified was interactivity. In the sex-toy website, it was used as proof-of-evidence for performance and legitimacy. In the fetish campaign, it was used as an incentive to increase user engagement. Most of the other elements can be transferred to print media and those that cannot (like sound) are not as crucial in meaning making. The simulation of sexual behaviour by clicking naked bodies on a screen (as in the second website) is impossible to accomplish in traditional media.

Another finding was that concepts of sex and technology seemed to be positioned as opposites. The way this was achieved proved to be unpredictable. In both examples, advertisers chose not to accentuate the products' main use (pleasure or everyday activities). A sex-toy webpage would be expected to be more explicit but its use of connotations stripped it of obscenity; the website of a technology store-whose clients could very well be adolescents-was almost pornographic. It is hypothesized that this could be a technique to achieve some balance, to attract customers concerned with trust rather than pleasure or to provide technology products some of the appeal they lack through sexually charged promotional campaigns.

Of course, this cannot be generalized, as other factors also come into play like the identity of the target audience, cultural context, etc. There are definitely exceptions, but while there are examples of technology products that rely on their technical specifications as a selling point, there are few to no sex related products in the digital media that openly promote their ability to enhance one's sexual pleasure. It would be interesting to study if this takes place by choice or not. Quoting the advertising policies of Facebook ${ }^{7}$ for contraceptives: "[a]ds [...] must focus on the contraceptive features of the product and not on sexual pleasure". It seems that sexual pleasure itself-not being explicit-is taboo in digital media. Whether this is a legal issue or not, it is an interesting reflection of contemporary digital culture.

\footnotetext{
${ }^{7}$ See https://www.facebook.com/policies/ads/prohibited_content/adult_products_or_ services\# (last accessed on14/10/2018).
} 
TECHNOLOGY SELLING SEX...

\section{References}

Barthes, Roland. 1964. Rhétorique de l'image. Communications 4: 40-51.

Barthes, Roland. 2002 [1973]. S/Z. Oxford: Blackwell.

Budd, Mike, Craig, Steve \& Steinman, Clayton M. 1999. Consuming environments: television and commercial culture. New Brunswick, NJ: Rutgers University Press.

Crissel, Andrew. 1994. Understanding radio. London; New York: Routledge.

Hodge, Robert, \& Kress, Gunther. 1988. Social semiotics. Cambridge: Polity Press.

Kress, Gunther, \& van Leeuwen, Theo. 2001. Multimodal discourse: The modes and media of contemporary communication. London: Arnold.

Kristeva, Julia. 1986. Word, Dialog and Novel, in Moi, Toril (ed.). 1986. The Kristeva Reader. New York: Columbia University Press: 34-61.

Lotman, Juri. 2009. Culture and explosion. Berlin, Germany: Mouton de Gruyter.

Nedeljković, Uroš, Puškarević, Irma, Novaković, Dragoljub \& Pintier, Ivan. 2013. The effectiveness of sex appeal in print ads in relation to a visual register of the message: Articulating a new framework. Marketing. 44: 247-263.

O’ Halloran, K. L. 2011 (in press). Multimodal Discourse Analysis. In Hyland K. \& Paltridge B. (eds). Companion to Discourse. London and New York: Continuum.

Peirce, Charles Sanders. 1931-1966. Collected papers of Charles Sanders Peirce. Charles Hartshorne, Paul Weiss, Arthur Burks (eds.), 8 volumes. Cambridge, MA: Belknap Press, Harvard University Press.

Robinson, Helen, Wysocka, Anna \& Hand, Chris. 2007. Internet advertising effectiveness - The effect of design on click-through rates for banner ads. International Journal of Advertising 26 (4): 527-541.

Roehm, Harper A. \& Haugtvedt, Curtis P. 1999. Understanding interactivity of cyberspace advertising, in Schumann D.W. \& Thorson E. (eds). 1999. Advertising and the World Wide Web. Mahwah, NJ: Lawrence Erlbaum: 27-40. 
Sebeok, Thomas 1987. Messages in the marketplace. In: Donna Jean Umiker-Sebeok (ed.), Marketing and semiotics: new directions in the study of signs for sale. Berlin, New York \& Amsterdam: Mouton de Gruyter: 21-30.

Stam, Robert. 1992. From Realism to Intertextuality, in: Stam, Robert Burgoyne Robert \& Flitterman-Lewis, Sandy. New Vocabularies in Film Semiotics. Structuralism, Post-Structuralism and Beyond. London \& NewYork, Routledge: 184-221.

Stewart, D.W. \& Pavlou, P.A. 2002. From Consumer Response to Active Consumer: Measuring the Effectiveness of Interactive Media. Journal of the Academy of Marketing Science 30(4): 376-96.

Thibault, Paul J. 2000. The multimodal transcription of a television advertisement: Theory and practice, in Baldry, Anthony (ed.). 2000. Multimodality and multimediality in the distance learning age: Papers in english linguistics. Campobasso, Italy: Palladino Editore: 311-385.

Treise, Debbie, Weigold, Michael F., Conna, Jenneane \& Garrison, Heather. 1994. Ethics in advertising: Ideological correlates of consumer perceptions. Journal of Advertising 23: 59-69.

Uspenskij, B.-A., V.-V. Ivanov, V.-N. Toporov, A.-M. Pjatigorskij \& J.M. Lotman 2003 [1973]. Theses on the semiotic study of cultures (as applied to slavic texts). In M. Gottdiener, K. Boklund-Lagopoulou \& A.-Ph. Lagopoulos (eds.), Semiotics, volume I, London, Thousand Oaks, New Delhi: Sage, 293-316.

Van Leeuwen, Theo. 2001. Semiotics and Iconography, in van Leeuwen, Theo \& Jewitt, Carey (eds.). 2001. Handbook of Visual Analysis. London; Thousand Oaks; New Delhi: Sage Publications: 92-118.

Van Leeuwen, Theo. 2006. Towards a semiotics of typography. Information Design Journal 14(2): 139-155.

Van Leeuwen, Theo. 2011. The Language of Colour. London \& New York: Routledge. 